\title{
A new method for using historical street photography collections as a primary source for cartographic production
}

\author{
Antonio Suazo ${ }^{\text {a }}$ \\ ${ }^{a}$ Centro Nacional de Conservación y Restauración, Antonio Suazo - asuazol @ uc.cl
}

Keywords: Historical cartography, Historical photography, Geoinformation management

\begin{abstract}
:
The production of historical cartographies with the aid of digital tools has become in recent years a very active field of study, especially in urban heritage research. In this way, contributions from disciplines such as computer vision or remote sensing allow today to integrate data from various documentary records, enriching the available urban historiography, and enabling new readings on the relationship between historical cartography and contemporary sources of information. Despite this, little attention has been paid to the use of urban street photography, which continues to be used mostly to confirm or validate cartographic hypotheses, but not as a primary source of information. Among other causes, this is because there are no standardized procedures to extract the information directly from the photographs, nor with methods that allow addressing the divergences between captures from various locations and times.
\end{abstract}

To overcome this situation, a new methodology is proposed to incorporate collections of historical photographs into a cartographic creation process, for the recovery and direct use of the information contained in them. Throughout a workflow, the proposal provides special support for two sub-processing steps: i) the possibility of comparatively studying the information from various photographs, and ii) the possibility of managing and taking into account the differences in dates between different shots. For this, the proposal transfers the recovered information from the photographs (in a 3D coordinate system) to a single cartographic representation (in a 2D coordinate system), to support that data management and decision making take place directly in the map view. This is intended to overcome the practice of using the map to 'pass clean' discoveries made with other means and to restore instead the notion of cartographic representation as a detection and direct investigation tool.

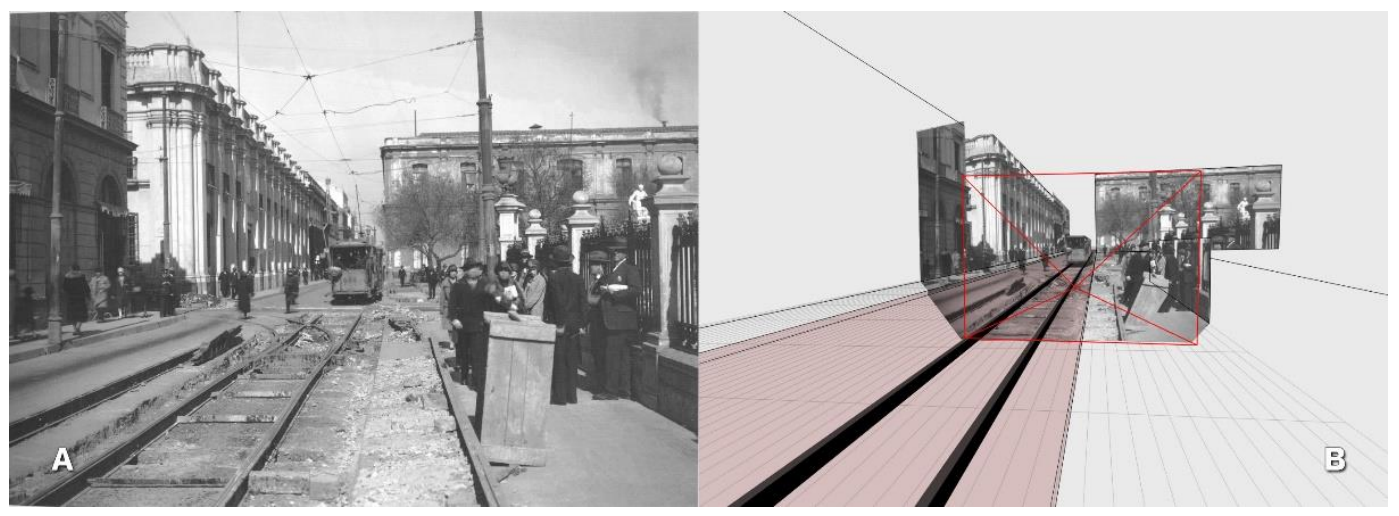

Figure 1. (left) Original photograph depicting a disappeared urban set; (right) processed photograph, providing spatial clues for railway lines and street profile identification.

The work considers the evaluation of the proposed method through the application in a case study. We worked with the restitution of the disappeared tram system of Santiago, Chile (1900-1945) through the cartographic representation of its extinct network of railway lines, of which only some isolated fragments remain. The visual documentation was provided by the Chilectra photographic archive (1921-27) -currently managed by the Photographic Archive of the National Library of Chile- which documented the extent of the tracks layout and its installation process (Figure 1a). Thus, around 200 scanned historical photographs were reviewed and processed with the proposed method, and their information made available to a cartographic production and management process (Figure 1b), based on the historical cartography of Santiago from Hidalgo et al (2011) and Salas (2012). Finally, the obtained data is evaluated (Figure 2), identifying scopes on the recovered information and on the characteristics that the photographs must meet in the first instance to be processed. 


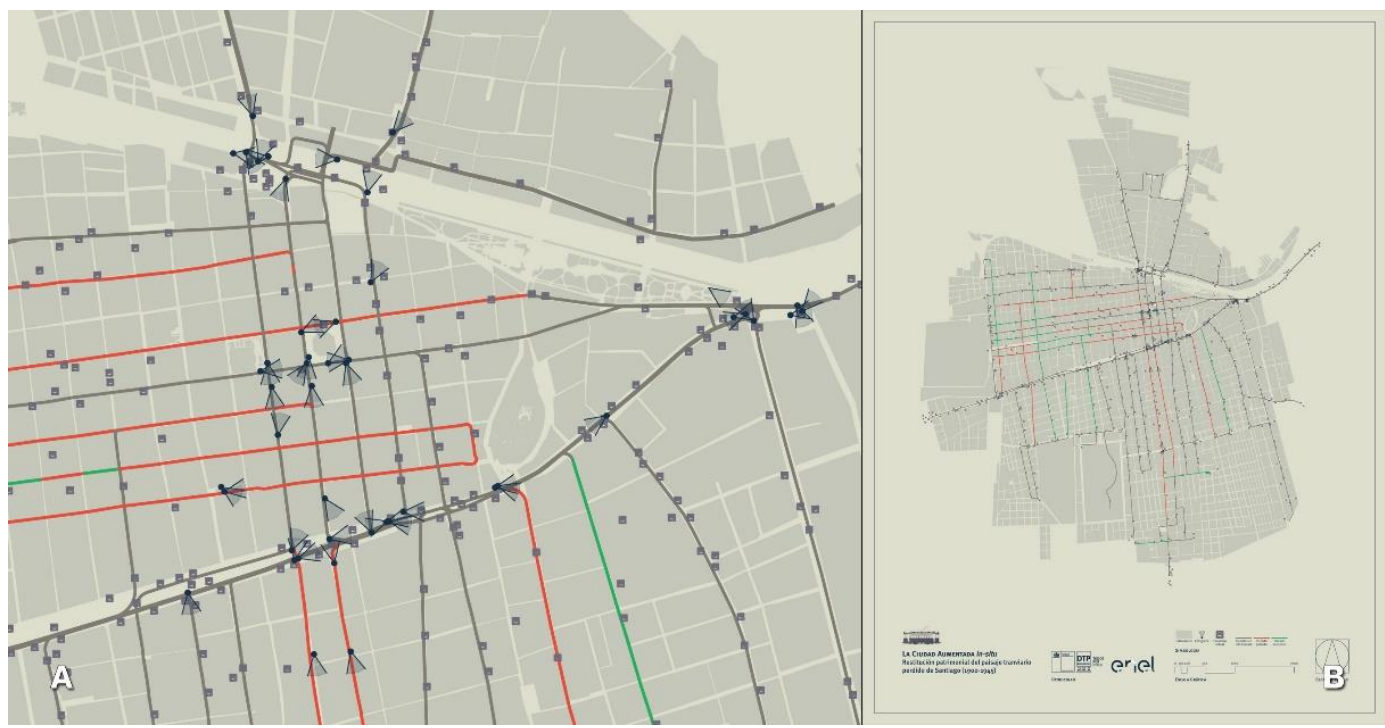

Figure 2. Mapping production result, exhibiting disappeared railway lines in red and remaining fragments in green, as well as photographs position and orientation: (left) detail; (right) general view.

The satisfactory results obtained show that the proposed approach and method allow historical photography to be used directly within a cartographic process, as a primary source of information. This reinforces the idea of the place that corresponds to these records within the spectrum of historiographic sources, along with textual, planimetric, and other descriptions of urban interest. Likewise, the work reflects on the approach that should prevail to use the map as a research tool, and on the possibilities that such a process opens, significantly improving the use of historical photography for the study of urban heritage with cartographic representations.

\section{Acknowledgements}

This work was partially funded by the National Fund for Scientific and Technological Development (Fondecyt) Grant $\mathrm{N}^{\circ}$ 1150308, with additional support by the National Center for Conservation and Restoration from the Ministry of Arts, Culture and Heritage, and valuable help from the Photographic Archive of the National Library of Chile, as well as the junior research group Evidencia Visual, Chile.

\section{References}

Chilectra Metropolitana S.A., 1921-27. Chilectra Photographic Archive. Available in Biblioteca Nacional Digital de Chile http://www.bibliotecanacionaldigital.gob.cl/bnd/629/w3-article-554178.html. Accessed on 12/5/2020.

Hidalgo, G., Rosas, J., Strabucchi, W., 2012. Cartographic Representation as the Production of Knowledge: Theoretic Reflections Regarding the Creation of the Map of Santiago in 1910. In ARQ, Santiago, Chile, Vol 80, pp. 62-75. https://dx.doi.org/10.4067/S0717-69962012000100016.

Salas, A., 2014. La ciudad de los tranvías, Santiago 1857 -1929: De cuadrícula a territorio reticular: Puntos, líneas, redes y lugares. Unpublished doctoral dissertation, Universidad Católica de Chile, Santiago, Chile. 